\title{
Synthesis of Co(II), Ni(II) and Cu(II) Complexes from Schiff base Ligand and Reactivity Studies with Thermosetting Epoxy Resin
}

\author{
B. Lakshmi, ${ }^{\dagger}$ K. N. Shivananda, ${ }^{\dagger,},{ }^{*}$ Gouda Avaji Prakash, ${ }^{\ddagger}$ Krishna Reddy K. Rama, ${ }^{\dagger}$ and K. N. Mahendra ${ }^{\dagger, *}$ \\ ${ }^{\dagger}$ Department of Studies in Chemistry, Central College Campus, Bangalore University, Bangalore-560001, Karnataka, India \\ *E-mail: mahendrakadidal@yahoo.co.in (K.N. Mahendra) \\ Department of Organic Chemistry, Indian Institute of Science, Bangalore-560012, Karnataka. India \\ ${ }^{\S}$ Schulich Faculty of Chemistry, Technion - Israel Institute of Technology, Technion City, Haifa -32000, Israel \\ ${ }^{*}$ E-mail: shivananda_kn@yahoo.com (K.N. Shivananda) \\ Received November 23, 2010, Accepted March 24, 2011
}

\begin{abstract}
A hybrid thermosetting maleimido epoxy compound 4-( $N$-maleimidophenyl) glycidylether ( $N$-MPGE) containing $\mathrm{Co}(\mathrm{II}), \mathrm{Ni}(\mathrm{II})$ and $\mathrm{Cu}(\mathrm{II})$ ions was prepared by curing $N$-MPGE and tetradentate Schiff base $\mathrm{Co}$ (II), $\mathrm{Ni}$ (II) and $\mathrm{Cu}$ (II) complexes. The curing polymerization reaction of $N$-MPGE with metal complexes as curing agents was studied. The cured samples were studied for thermal stability, chemical (acid/alkali/solvent) and water absorption resistance and homogeneity of the cured systems. The tetradentate Schiff base, 3-[(Z)-2piperazin-1-yl-ethylimino]-1,3-dihydro indol-2-one was synthesized by the condensation of Isatin (Indole-2, 3dione) with 1-(2-aminoethyl)piperazine (AEP). Its complexes with $\mathrm{Co}(\mathrm{II}), \mathrm{Ni}(\mathrm{II})$ and $\mathrm{Cu}(\mathrm{II})$ have been synthesized and characterized by microanalysis, conductivity, Uv-Visible, FT-IR, TGA and magnetic susceptibility measurements. The spectral data revealed that the ligand acts as a neutral tetradentate Schiff base and coordinating through the azomethine nitrogen, two piperazine nitrogen atoms and carbonyl oxygen.
\end{abstract}

Key Words : Isatin, Schiff base, Epoxy resin, Curing, Epichlorohydrin

\section{Introduction}

Isatin and its derivatives are special members in the Schiff base family. The simple isatin based Schiff base compounds having, acyl, aroyl and heteroacroyl Schiff bases have additional donor sites $>\mathrm{C}=\mathrm{O},>\mathrm{C}=\mathrm{N}-$, etc. These donor sites make them more flexible and versatile. This versatility has made them good chelating agents that can form a variety of complexes with various transition and inner transition metals and has attracted the attention of many researchers. ${ }^{1}$

Schiff bases were used as plasticizers and stabilizers for polymers, polymerization initiators, antioxidants, etc., They act as intermediates in preparative chemistry. In analytical chemistry, hydrazones find application in detection, determination and isolation of compounds containing the carbonyl group. More recently, they have been extensively used in detection and determination of several metals. They also find applications as indicators and spot test reagents. ${ }^{2}$

One of the major synthetic efforts is in the field of heatresistant epoxy polymers. The need for such polymers is their potential use as materials for air-craft, spacecraft, automotive and electronic components. Incorporation of transition metals into polymer chains offers a possibility to access new useful heat-resistant polymers. To date, the methods to prepare metal-containing epoxy polymers involve the use of metal chelates as the curing agents, ${ }^{3}$ organotransition-metal complexes as additives ${ }^{4}$ and synthesis of epoxy resins containing transition metal ions. ${ }^{5}$ It has been found that the metal-containing epoxy polymers possess high strength and thermal stability and can be used for industrial production of one-plate glass-reinforced plastic springs for large-loaded motor vehicles. ${ }^{6}$

On the other hand, epoxy resins modified with maleimide compounds also received attractive attentions, due to the similar curing conditions and processing properties of the epoxy resins and malemide. Maleimide epoxy resins usually showed appropriate properties between epoxy and maleimide resins. Thus, both the intercrossed and the interpenetrating systems (IPN) based on bismaleimides and epoxy resins were prepared which exhibited good thermal and mechanical properties Additionally, since imide groups could provide char formation in the condensed phase to improve polymers flame retardant properties, epoxy resins modified with imide compounds through chemical reactions or physical blending have been reported to show good flame retardant properties. $^{7}$

A survey of the literature reveals that no work has been carried out on the use of Schiff base-metal complexes as curing agents in maleimide epoxy resin or thermosetting epoxy resins. So it was considered worthwhile to study the use of Schiff base-metal complexes are user as curing agents in thermosetting epoxy resin. Each of the reactive groups might form cross-linking networks under thermal curing reaction with these Schiff-bases metal complexes to bring about high cross-linking density. The cured samples were found to have good thermal stability, chemical resistance and water absorption resistance. However, these cured samples exhibited homogeneity with no phase separation which was confirmed by scanning electron microscopy (SEM) and definitional scanning colorimetric studies. 


\section{Experimental Section}

Materials. The chemicals employed were of AR grade. All the solvents were purified by standard methods. Maleic anhydride, 4-aminophenol and isatin were purchased from S.D.Fine chemicals. Benzyl tri-methyl ammonium chloride (BTAC) and 1-(2-aminoethyl) piperazine (AEP) were supplied by Aldrich Chemical Co. Dimethylformamide (DMF), p-toluenesulphonic acid, toluene, sodium bicarbonate, ethyl acetate, $\mathrm{H}_{2} \mathrm{SO}_{4}, \mathrm{HNO}_{3}, \mathrm{HCl}, \mathrm{C}_{6} \mathrm{H}_{6}, \mathrm{CH}_{3} \mathrm{CH}_{2} \mathrm{OH}, \mathrm{NH}_{3}$ and $\mathrm{NaOH}$ were obtained from Merck Chemicals.

Analysis and Physical Measurements. The micro analysis of the samples was carried out using Carlo Ebra analyser. The metal contents were estimated by standard methods. ${ }^{8}$ The conductivity measurements were made using a systronics conductivity meter 304 with a dip type conductivity cell with a cell constant $1 \mathrm{~cm}^{-1}$. The magnetic susceptibility measurements were carried out at room temperature using Faraday Balance. Electronic spectra were recorded in DMF in the range 900-350 nm using shimadzu UV3101 PC UV-VIS-NIR scanning spectrophotometer. ${ }^{1} \mathrm{H}-$ NMR spectra of the ligand and its complexes were obtained using Bruker AMX $400 \mathrm{MHz}$ FT- NMR spectrometer. IR spectra of samples in $\mathrm{KBr}$ pellets were recorded in the region $4000-600 \mathrm{~cm}^{-1}$ on a Nicolet impact $400-D$ FT-IR spectrometer. The far IR spectra of the complexes in the region 600$250 \mathrm{~cm}^{-1}$ were recorded using a Perkin Elmer instruments, Spectrum One FT-IR spectrometer. The mass spectrum of the ligand was recorded using an ESI-MS Bruker Daltronics mass spectrometer. TGA studies of the complexes were carried out using Perkin-Elmer Thermogravimetric analyser TGA 7 with a scan rate of $10{ }^{\circ} \mathrm{C}$ per minute in nitrogen atmosphere.

Preparation of Schiff Base. The Schiff base was prepared by the reported method. ${ }^{9}$ Equimolar ethanolic solutions (50 $\mathrm{mL}$ each) of isatin and 1-(2-aminoethyl) piperazine were mixed and refluxed for about 1 hour. The solvent was removed under vacuum and the product was extracted with DCM and brine. The organic phase was dried with sodium sulfate, filtered, and evaporated under a vacuum. The product was separated by column chromatography with Ethyl acetate and petroleum ether (1:1) to get a quantitative yield $(>95 \%)$ (Scheme 1). The mass spectrum of the ligand (IsAEP, L) shows the parent molecular ion peak at 259 corresponding to the macrocyclic moiety $\left[\left(\mathrm{C}_{14} \mathrm{H}_{18} \mathrm{~N}_{4} \mathrm{O}\right)^{+}\right.$and molecular weight of 258 .

Preparation of Co (II), Ni (II) and Cu (II) Complexes. The metal complexes were prepared by adding ethanolic solution $(50 \mathrm{~mL})$ of the metal salt to the ligand $(100 \mathrm{~mL})$ in 1:1 molar ratio and reflux for about 3 hours. The reaction mixture was concentrated to a small volume, which on cooling precipitated, the metal complexes. They were filtered, washed with ethanol and dried in vacuum (Scheme 1).

Preparation of 4-( $\mathrm{N}$-maleimidophenyl) Glycidylether (N-MPGE). The thermosetting epoxy resin monomer was synthesized according to Scheme 2. Experimental procedure for the synthesis and characterization of $N$-MPGE is the same as given in a previous publication. ${ }^{10}$ (Yield $80 \%$; melting point, $45-50{ }^{\circ} \mathrm{C}$; Epoxy equivalent weight $=254$. IR $\left(\mathrm{KBr}, \mathrm{cm}^{-1}\right)$ : $715(\mathrm{C}=\mathrm{O}$ bending), 912 (oxirane-ring), 1248,

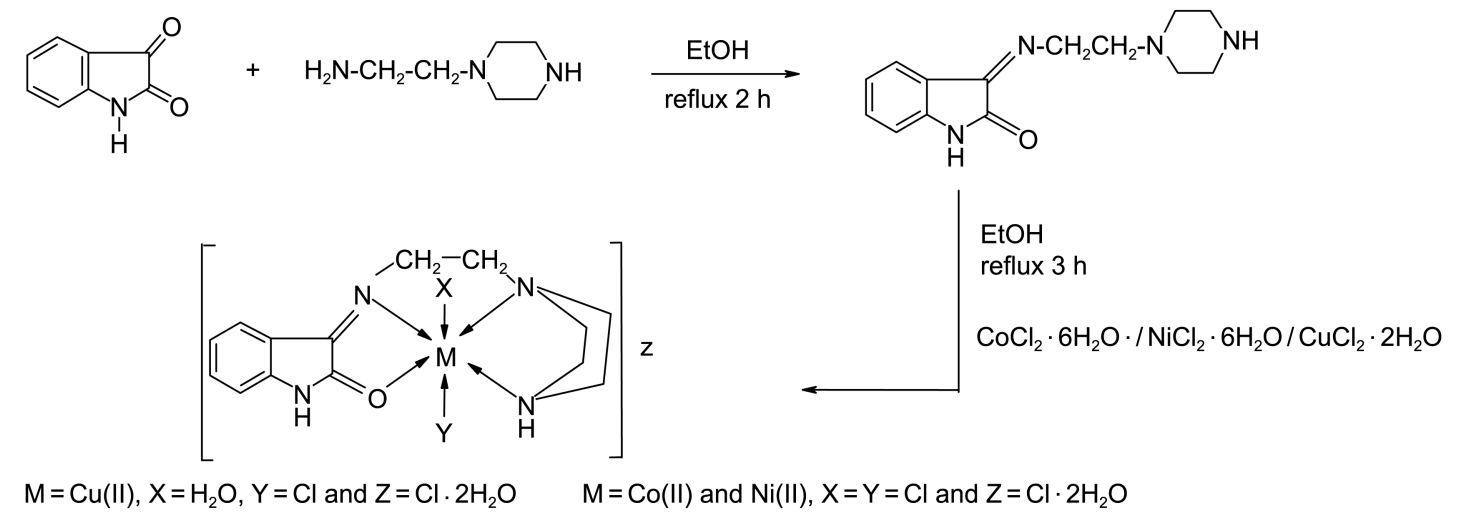

Scheme 1. Preparation of Schiff base and its $\mathrm{Co}(\mathrm{II}), \mathrm{Ni}(\mathrm{II})$ and $\mathrm{Cu}(\mathrm{II})$ complexes.

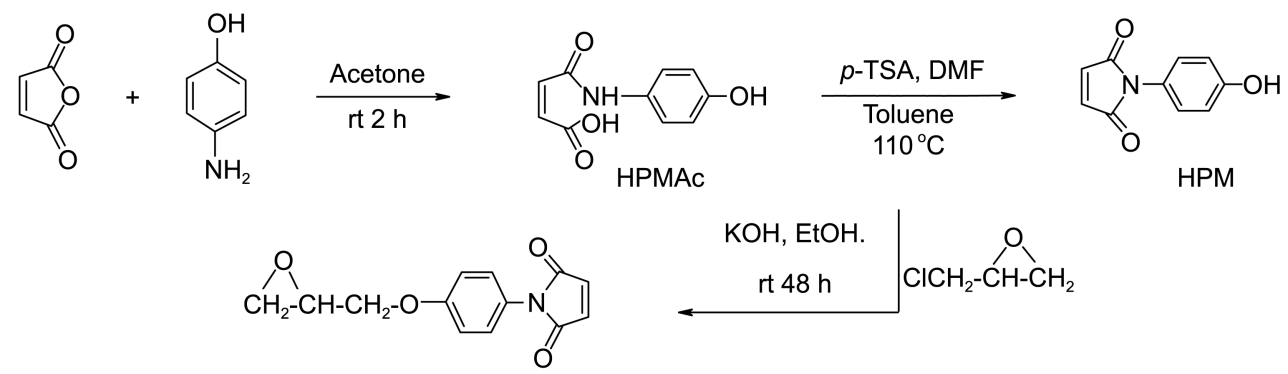

Scheme 2. Preparation of $N$-MPGE monomer. 
$1037\left(\mathrm{Ph}-\mathrm{O}-\mathrm{CH}_{2}\right), 1375$ (C-N stretching), $1609(\mathrm{C}=\mathrm{C}), 1715$ $(\mathrm{C}=\mathrm{O}$ symmetric stretching), $1781(\mathrm{C}=\mathrm{O}$ asymmetric stretching), and 3070 (C-H of imide group). ${ }^{1} \mathrm{H}-\mathrm{NMR}(400 \mathrm{MHz}$, DMSO- $\left.d_{6}, \mathrm{ppm}\right): 2.72$ and $2.87\left(2 \mathrm{H},-(\mathrm{O}) \mathrm{CH}_{2}\right) ; 3.68\left({ }^{1} \mathrm{H}\right.$, $\left.-\mathrm{CH}_{2} \mathrm{CH}(\mathrm{O})-\right) ; 4.13-4.26\left(2 \mathrm{H},-\mathrm{Ph}-\mathrm{OCH}_{2}-\right)$; $6.87(2 \mathrm{H},-\mathrm{CH}=\mathrm{CH}-)$; 7.03-7.54 (4H, aromatic protons).

Preparation of Cured Epoxy Resins. The cured epoxy resins were obtained from thermally curing of the thermosetting epoxy resin ( $N$-MPGE) with the Schiff base-metal complexes which were mixed together in methylethylketone as a solvent and cured in oven. The conditions of curing reactions are listed in Table 1.

Moisture Absorption and Chemical Resistance Measurements. The cured system was cut into small specimens of $25 \times 25 \mathrm{~mm}$ and edges of specimens were coated with the same matrix system in order to avoid the moisture absorption through cut edges by capillary action. All the dry specimens were weighed. To start with, the initial weights were noted at room temperature. The samples were then immersed in water/alkali/solvent/acid for different intervals of time and then taken out, dried and weighed.

\section{Results and Discussion}

All the metal complexes which are either colored or colorless solids are stable towards air and have high melting points (above $250{ }^{\circ} \mathrm{C}$ ). The complexes with the general formula $\left[\mathrm{MLCl}_{2}\right]$ where $\mathrm{M}=\mathrm{Co}(\mathrm{II}), \mathrm{Ni}(\mathrm{II})$ and $\mathrm{Cu}(\mathrm{II})$, gives the molecular formations of the type $\left[\mathrm{CuL}\left(\mathrm{H}_{2} \mathrm{O}\right) \mathrm{Cl}\right] \mathrm{Cl} \cdot 2 \mathrm{H}_{2} \mathrm{O}$, and $\left[\mathrm{MLCl}_{2}\right] \cdot 2 \mathrm{H}_{2} \mathrm{O}$. the complexes are insoluble in water and common organic solvents but are soluble in DMF and DMSO. Hence, the molecular weights could not be determined. Analytical data suggest that the metal to ligand ratio in all the complexes to be 1:1 (Table 2).The molar conductivity data for a $10^{-3} \mathrm{M}$ solution of the complexes in DMF show the $\mathrm{Cu}(\mathrm{II})$ complex to be 1:1 electrolytes and the other complexes as non-electrolytes (Table 2).

IR Spectra. Selected IR spectral bands for the ligand and its complexes are given in Table 3.The IR spectrum of the free ligand is characterized mainly by the strong bands at 3221,1717 , and $1618 \mathrm{~cm}^{-1}$ which are attributed to the stretching frequencies of $\mathrm{NH}$ (aromatic), $\mathrm{C}=\mathrm{O}$ and $\mathrm{C}=\mathrm{N}$ (azomethine), respectively. ${ }^{11}$ The band at $1717 \mathrm{~cm}^{-1}$ due to $\mathrm{C}=\mathrm{O}$ stretching in the spectrum of the ligand shifts to lower wave numbers by $8-16 \mathrm{~cm}^{-1}$ in the metal complexes indicating that the carbonyl oxygen atom is coordinated to the central metal ion. ${ }^{12}$ The band at $1618 \mathrm{~cm}^{-1}$ due to $\mathrm{C}=\mathrm{N}$ stretching in the spectrum of the ligand shifts to lower wave numbers in all the metal complexes by $7-10 \mathrm{~cm}^{-1}$ indicating that the azomethine nitrogen atom is coordinated to the metal ion. ${ }^{13}$ The band due to N-H (aliphatic) in the complexes appears at lower wave numbers relative to its position in the free ligand, thus clearly indicating the coordination of the ligand through the nitrogen atom of the $\mathrm{N}-\mathrm{H}$ group. The

Table 1. Curing conditions and thermal stability (TGA \& DSC) of cured systems ( $N$-MPGE with Complexes)

\begin{tabular}{cccccc}
\hline \multirow{2}{*}{ System } & \multirow{2}{*}{ Curing conditions } & \multicolumn{2}{c}{ Thermal stability } & \multicolumn{2}{c}{ DSC data } \\
\cline { 3 - 5 } & & IDT $\left({ }^{\circ} \mathrm{C}\right)$ & IPDT $\left({ }^{\circ} \mathrm{C}\right)$ & $\mathrm{T}_{\text {endo }}\left({ }^{\circ} \mathrm{C}\right)$ & $\mathrm{T}_{\text {exo }}\left({ }^{\circ} \mathrm{C}\right)$ \\
\hline$N$-MPGE $+\mathrm{Cu}(\mathrm{II})$ & $110^{\circ} \mathrm{C}(1 \mathrm{~h}), 150{ }^{\circ} \mathrm{C}(2 \mathrm{~h})$ & 410 & 540 & 70 & 360 \\
$N$-MPGE $+\mathrm{Ni}(\mathrm{II})$ & $110{ }^{\circ} \mathrm{C}(1 \mathrm{~h}), 150{ }^{\circ} \mathrm{C}(2 \mathrm{~h})$ & 405 & 530 & 68 & 340 \\
$N$-MPGE $+\mathrm{Co}(\mathrm{II})$ & $110{ }^{\circ} \mathrm{C}(1 \mathrm{~h}), 150{ }^{\circ} \mathrm{C}(2 \mathrm{~h})$ & 400 & 520 & 78 & 365 \\
\hline
\end{tabular}

Table 2. Analytical and physical data of the complexes

\begin{tabular}{|c|c|c|c|c|c|c|c|c|}
\hline \multirow{2}{*}{ Compound } & \multirow{2}{*}{ Yield (\%) } & \multirow{2}{*}{ Colour } & \multirow{2}{*}{$\mathrm{mp}\left({ }^{\circ} \mathrm{C}\right)$} & \multicolumn{4}{|c|}{ Elemental analysis (\%) Found (Calcd) } & \multirow{2}{*}{$\begin{array}{l}\text { Mol. Conductance* } \\
\left(\mathrm{ohm}^{-1} \mathrm{~cm}^{2} \mathrm{~mol}^{-1}\right)\end{array}$} \\
\hline & & & & $\mathrm{C}$ & $\mathrm{H}$ & $\mathrm{N}$ & $\mathrm{M}$ & \\
\hline IsAEP (L) & 90 & Brown & 220 & 60.65 & 7.21 & 20.25 & - & - \\
\hline$\left(\mathrm{C}_{14} \mathrm{H}_{18} \mathrm{~N}_{4} \mathrm{O} \cdot \mathrm{H}_{2} \mathrm{O}\right)$ & & & & $(60.86)$ & $(7.24)$ & $(20.29)$ & & \\
\hline \multirow[t]{2}{*}[\mathrm{CuLH}_{2}\mathrm{O}\cdot\mathrm{Cl}]{$\mathrm{Cl} \cdot 2 \mathrm{H}_{2} \mathrm{O}$} & 85 & Light green & 180 & 39.98 & 5.95 & 12.0 & 15.04 & 86 \\
\hline & & Brown & & $(39.16)$ & $(5.13)$ & $(13.05)$ & $(14.90)$ & \\
\hline \multirow[t]{2}{*}[\mathrm{CoLCl}_{2}]{} & 80 & & $>250$ & 43.77 & 4.82 & 14.25 & 15.02 & 14 \\
\hline & & Reddish & & $(43.29)$ & $(4.64)$ & $(14.43)$ & $(15.20)$ & \\
\hline$\left[\mathrm{NiLCl}_{2}\right]$ & 80 & brown & $>250$ & $\begin{array}{c}43.01 \\
(43.33)\end{array}$ & $\begin{array}{c}4.84 \\
(4.64)\end{array}$ & $\begin{array}{c}14.26 \\
(14.44)\end{array}$ & $\begin{array}{c}14.98 \\
(15.13)\end{array}$ & 33 \\
\hline
\end{tabular}

*DMF solution

Table 3. Selected IR frequencies $\left(\mathrm{cm}^{-1}\right)$ and UV-visible spectral data $\left(\mathrm{cm}^{-1}\right)$ of the complexes

\begin{tabular}{cccccccccc}
\hline Ligand/Complex & $\begin{array}{c}v_{\mathrm{O}-\mathrm{H}} \\
\left(\mathrm{H}_{2} \mathrm{O}\right)\end{array}$ & $\begin{array}{c}v_{\mathrm{NH}} \\
\text { (isatin) }\end{array}$ & $v_{\mathrm{C}=\mathrm{O}}$ & $v_{\mathrm{C}=\mathrm{N}}$ & $\begin{array}{c}v_{\mathrm{NO}} \\
(\text { Coordinated) }\end{array}$ & $v_{\mathrm{M}-\mathrm{N}}$ & $v_{\mathrm{M}-\mathrm{O}}$ & $v_{\mathrm{M}-\mathrm{Cl}}$ & $\begin{array}{c}\lambda_{\max } \\
\left(\mathrm{cm}^{-1}\right)\end{array}$ \\
\hline IsAEP $(\mathrm{L})$ & 3417 & 3240 & 1717 & 1618 & - & - & - & - & - \\
{$\left[\mathrm{CuL}\left(\mathrm{H}_{2} \mathrm{O}\right) \mathrm{Cl}\right] \mathrm{Cl} \cdot \mathrm{H}_{2} \mathrm{O}$} & 3447 & 3241 & 1709 & 1610 & - & 480 & 460 & 320 & 14388 \\
{$\left[\mathrm{CoLCl}{ }_{2}\right]$} & - & 3241 & 1709 & 1610 & - & 493 & 420 & 326 & 15748,19230 \\
{$\left[\mathrm{NiLCl}_{2}\right]$} & - & 3249 & 1702 & 1612 & - & 490 & 450 & 326 & $10050,14925,23529$ \\
\hline
\end{tabular}


band due to the C-H stretching frequency of the $\mathrm{N}-\mathrm{CH}_{2}$ group in the complexes either disappears or shifts to lower wavelength region. In the case of disappearance, these bands probably shift to lower wave number region $\left(2,900 \mathrm{~cm}^{-1}\right)$ and overlap with stretching vibrational bands of other $\mathrm{C}-\mathrm{H}$ bonds of the complexes. This shift indicates that the nitrogen atom of the $\mathrm{N}-\mathrm{CH}_{2}$ group no longer has a lone pair of electrons and it acquired a partial positive charge due to its coordination with the metal ion. Similar observations were made by earlier authors. ${ }^{14} \mathrm{~A}$ broad band around the 3450 $3340 \mathrm{~cm}^{-1}$ is observed in the infrared spectra of the complexes of $\mathrm{Cu}(\mathrm{II})$. This may be assigned to $\mathrm{OH}$ stretching frequencies of the H-Bonded water molecule. Further the IR spectra of the complexes of $\mathrm{Cu}(\mathrm{II})$ and $\mathrm{Co}$ (II) exhibit new bands at $480-540,420-460$ and $330-335 \mathrm{~cm}^{-1}$, which may be assigned to $\mathrm{M}-\mathrm{O}, \mathrm{M}-\mathrm{N}$ and $\mathrm{M}-\mathrm{Cl}$ (terminal) stretching modes respectively. ${ }^{15}$ Thus the Schiff base ligand coordinates to the central metal ions as a neutral ONNN tetradentate ligand via carbonyl oxygen of Isatin moiety, azomethine nitrogen and two piperazine nitrogen atoms forming three five-membered chelating rings.

UV-visible and Magnetic Susceptibility Measurements. The $\mathrm{Co}(\mathrm{II}), \mathrm{Ni}(\mathrm{II})$ and $\mathrm{Cu}(\mathrm{II})$ complexes show magnetic moments of 3.92, 3.15 and 1.92 B.M, respectively which is characteristic of mononuclear, octahedral cobalt(II) $\left(d^{7}, 3\right.$ unpaired electrons), nickel(II) ( $d^{8}, 2$ unpaired electrons) and copper(II) $\left(d^{9}, 1\right.$ electron) complexes. ${ }^{16}$ The electronic spectral data of the complexes in DMF are presented in Table 3.

The broad band centered at $14390 \mathrm{~cm}^{-1}$ appearing as an envelope in the copper(II) complex, assigned to the ${ }^{2} \mathrm{E}_{\mathrm{g}} \rightarrow$ ${ }^{2} \mathrm{~T}_{2 \mathrm{~g}}$ transitions indicates octahedral geometry. ${ }^{17}$ The electronic spectrum of the cobalt(II) complex shows two bands at $15748,19230 \mathrm{~cm}^{-1}$ which are assigned to ${ }^{4} \mathrm{~T}_{1 \mathrm{~g}} \rightarrow{ }^{4} \mathrm{~A}_{2 \mathrm{~g}}(\mathrm{~F})$ $\left(v_{2}\right)$ and ${ }^{4} \mathrm{~T}_{1 \mathrm{~g}}(\mathrm{~F}) \rightarrow{ }^{4} \mathrm{~T}_{1 \mathrm{~g}}(\mathrm{P})\left(v_{3}\right)$ transitions, respectively, as expected for an octahedral cobalt(II) complex. ${ }^{18}$ The electronic spectrum of the nickel(II) complex exhibits three bands at 10050,14925 and $23529 \mathrm{~cm}^{-1}$, attributable to ${ }^{3} \mathrm{~A}_{2 \mathrm{~g}}(\mathrm{~F}) \rightarrow{ }^{3} \mathrm{~T} 2 \mathrm{~g}(\mathrm{~F})\left(v_{1}\right),{ }^{3} \mathrm{~A}_{2 \mathrm{~g}}(\mathrm{~F}) \rightarrow{ }^{3} \mathrm{~T} 1 \mathrm{~g}(\mathrm{~F})\left(\mathrm{V}_{2}\right)$ and ${ }^{3} \mathrm{~A}_{2 \mathrm{~g}}(\mathrm{~F})$ $\rightarrow{ }^{3} \mathrm{~T}_{1 \mathrm{~g}}(\mathrm{P})\left(v_{3}\right)$ transitions, respectively, for an octahedral $\mathrm{Ni}(\mathrm{II})$ complex.

Thermo Gravimetric Studies. TGA studies of the complexes were carried out in nitrogen atmosphere at the rate of $10^{\circ}$ per minute up to $700{ }^{\circ} \mathrm{C}$. In the thermal decomposition studies of the complexes a general pattern is observed where the water of hydration is lost followed by the loss of uncoordinated chloride/nitrate, coordinated chloride/nitrate, ligand molecules and the decomposition of the complex to finally yield the respective metal oxides at higher temperatures (Table 4).

Curing Reactions of $N$-MPGE with Metal Complexes. Epoxy resin can be cured using amines, anhydrides, fatty acids, acrylics, and amides as curing agents to study the effect on their curing rate and related properties to obtain epoxy polymers. ${ }^{19}$ Therefore, the Schiff base-metal complexes, which also contain amine groups in their molecules, were then applied as curing agents for $N$-MPGE. The curing of systems, obtained by reacting between $N$-MPGE with Schiff based metal complexes, was carried out based on their hydrogen equivalent weights. $N$-MPGE monomer and metal complexes taken on an aluminum foil of about $10 \mathrm{~cm}$ diameters were dissolved in methylethylketone to form a homogeneous solution. After evaporating the solvent at ambient temperature the mixture was cured with specific curing condition to result in cured resins. The curing process converts the $N$-MPGE into a hard, infusible and rigid material; the curing conditions are listed in Table 1.

Scheme 3 shows the curing mechanism of $N$-MPGE with the metal complexes which is proposed to involve a ring opening of the epoxy group of $N$-MPGE by the amine groups of the complex to give an alcohol, which can then open another epoxy group of $N$-MPGE forming a highly cross linked, three dimensional network. These reactions occur repeatedly to produce the cross-linked metal-containing maleimide epoxy compounds.

Maleimide group of $N$-MPGE is well known that, the maleimide groups might crosslink through self-addition reaction (Scheme 4) under heating. ${ }^{20}$ Therefore, while curing $N$-MPGE with metal complexes, all the three above-mentioned reactions might occur. In this work, the curing compositions were taken with the same stoichiometric amounts of the amine curing agent and oxirane groups. Therefore, most of the amine groups are expected to react with oxirane groups at low temperature region. Since almost no amino group was left to react with maleimide group, only self-addition reaction occurred for maleimide groups in the curing reaction. The resulting products obtained were therefore supposed to have high cross linking densities.

Differential Scanning Calorimetric (DSC) Studies of Cured Systems. The homogeneity of the cured systems is confirmed by Dynamic DSC thermograms which are repre-

Table 4. TGA data of the complexes

\begin{tabular}{|c|c|c|c|c|c|}
\hline Complex & Stage & $\begin{array}{l}\text { Temp. } \\
\left({ }^{\circ} \mathrm{C}\right)\end{array}$ & $\begin{array}{c}\text { Weight loss } \\
\% \text { Found (\%Calc.) }\end{array}$ & Species lost & Residue \\
\hline \multirow[t]{3}{*}[\mathrm{CuL}(\mathrm{H}_{2}\mathrm{O})\mathrm{Cl}]{$\mathrm{Cl} \cdot \mathrm{H}_{2} \mathrm{O}$} & 1 & 100 & $4.5(4.19)$ & Lattice water & $\mathrm{CuO}$ \\
\hline & 2 & $180-250$ & $21.0(20.74)$ & $2 \mathrm{Cl}+$ Coordinated water & \\
\hline & 3 & 370 & $61.00(60.13)$ & $\mathrm{L}$ & \\
\hline \multirow[t]{2}{*}[\mathrm{CoLCl}_{2}]{} & 1 & $250-300$ & $18.7(18.30)$ & $2 \mathrm{Cl}$ (coordinated) & $\mathrm{Co}_{2} \mathrm{O}_{3}$ \\
\hline & 2 & 370 & $66.8(66.49)$ & $\mathrm{L}$ & \\
\hline \multirow[t]{2}{*}[\mathrm{NiLCl}_{2}]{} & 1 & $240-290$ & $18.0(18.32)$ & $2 \mathrm{Cl}$ (coordinated) & $\mathrm{NiO}$ \\
\hline & 2 & 350 & $67.5(66.55)$ & $\mathrm{L}$ & \\
\hline
\end{tabular}




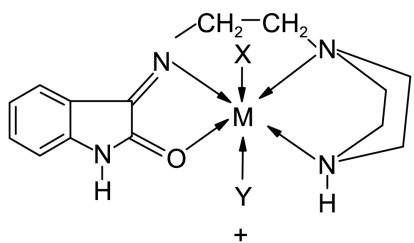

$: \mathrm{O:}$

$2 \mathrm{CH}_{2}-\mathrm{CH}-\mathrm{CH}_{2}-\mathrm{O}-\mathrm{C}_{6} \mathrm{H}_{4}-$<smiles>CC[18CH]OCC(C)C</smiles>

$\mathrm{OH}$

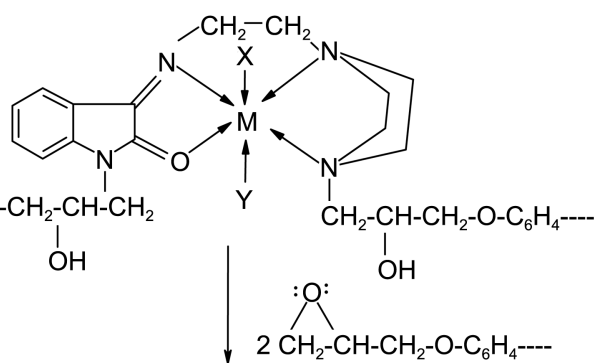

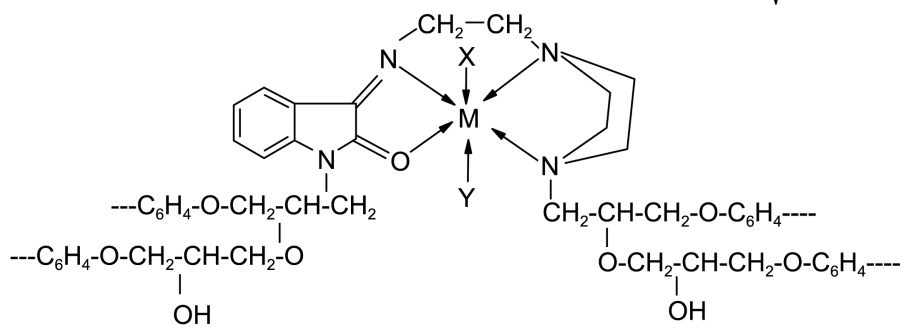

Scheme 3. The reaction mechanism of oxirane ring with metal complexes.

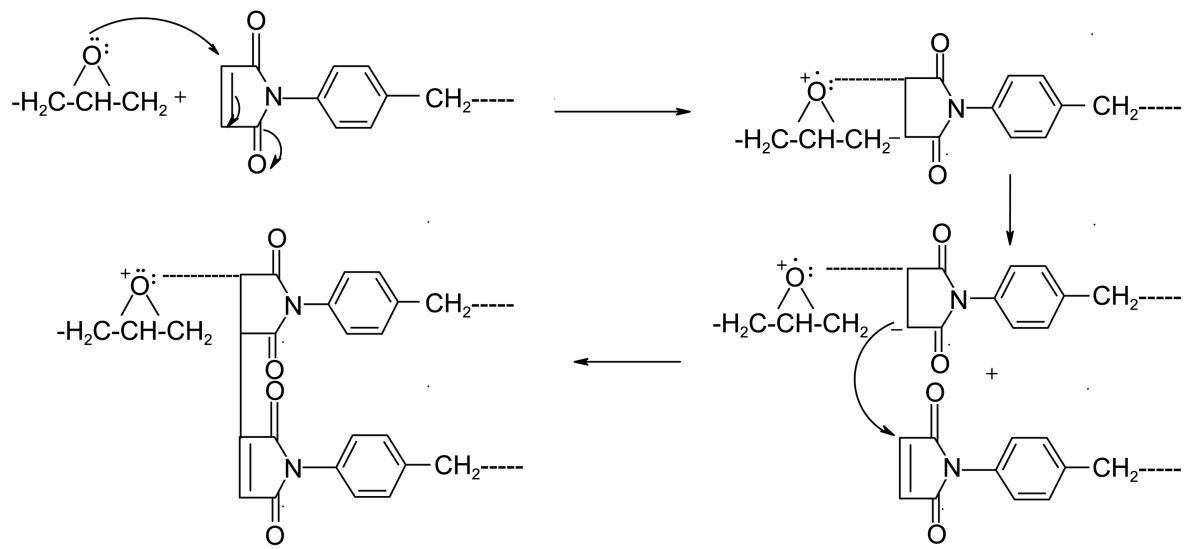

Scheme 4. Self-addition reaction of maleimide groups of $N$-MPGE monomer.

sented in Figure 1. The dynamic scans were performed at a heating rate of $10^{\circ} \mathrm{C} / \mathrm{min}$ and the data are summarized in Table 1. From Figure 1 it is clear that all the cured systems exhibit similar behavior. The peak at 70 to $90{ }^{\circ} \mathrm{C}$ corresponds to the melting point of the cured epoxy systems. The peak at

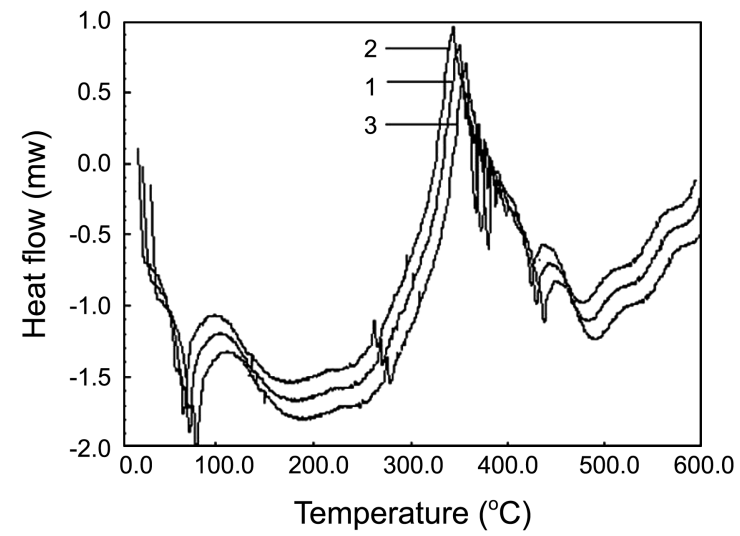

Figure 1. Dynamic DSC thermograms of the three systems 1). $N$ MPGE + Cu(II) complex, 2) $N$-MPGE + Ni(II) complex, and 3). $N$-MPGE + Co(II) complex. around 290 to $320{ }^{\circ} \mathrm{C}$ is attributed to the exothermic curing reactions of the $N$-MPGE monomer with amine systems, and the maximum of the exothermic peak obtained at 330-350 ${ }^{\circ} \mathrm{C}$. The completion of curing process indicates the absence of exotherm peaks in the post cure in the epoxy-amine

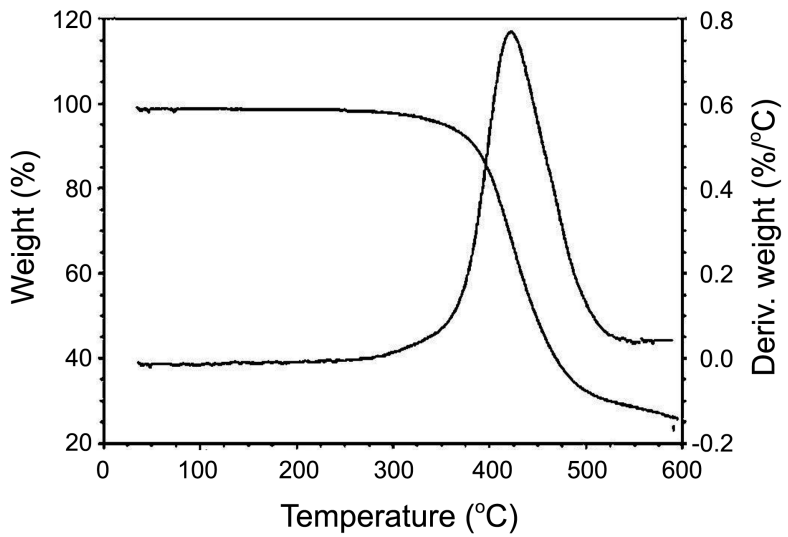

Figure 2. Thermogravimetric analysis (TGA) of $N$-MPGE with $\mathrm{Cu}$ (II) complex. 
systems. ${ }^{10,20}$

Thermal Properties of the Cured Systems. The thermal stability of the cured $N$-MPGE containing $\mathrm{Co}(\mathrm{II}), \mathrm{Ni}(\mathrm{II})$ and $\mathrm{Cu}(\mathrm{II})$ ions was investigated with thermogravimetric analysis (Fig. 2). The enhancement of the thermal stability due to incorporation of metal ions into $N$-MPGE was thus demonstrated. ${ }^{3,7}$ The thermograms of the cured $N$-MPGE contain-

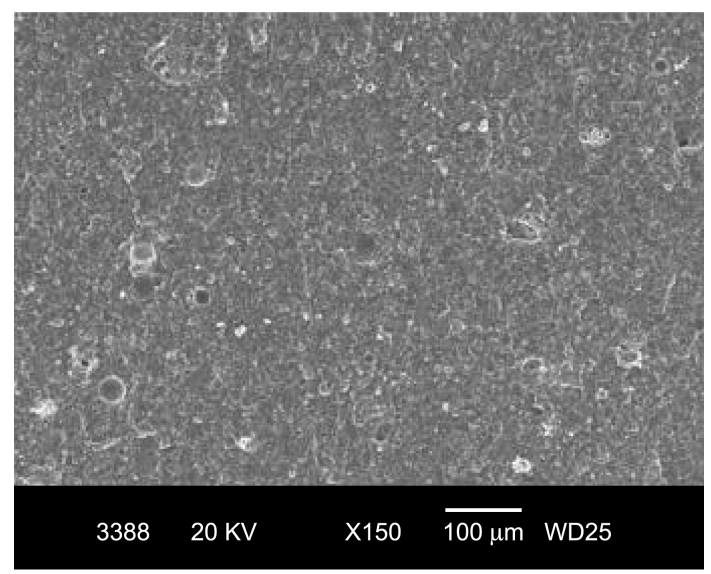

1) N-MPGE + Cu(II) complex

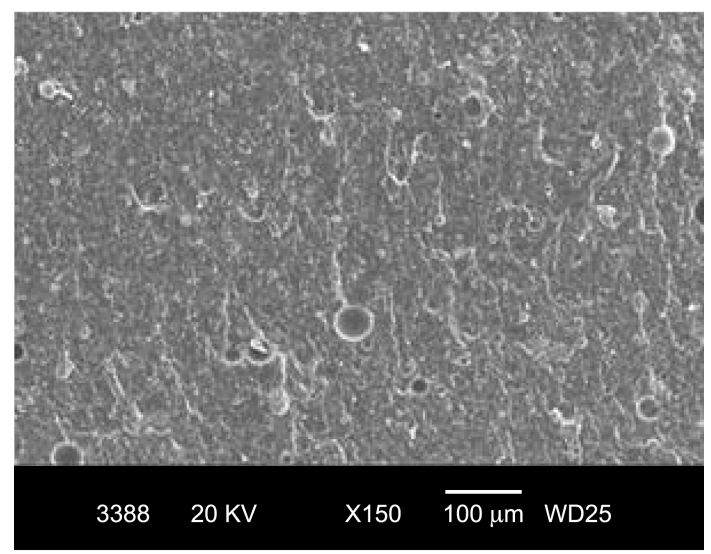

2) N-MPGE + Ni(II) complex

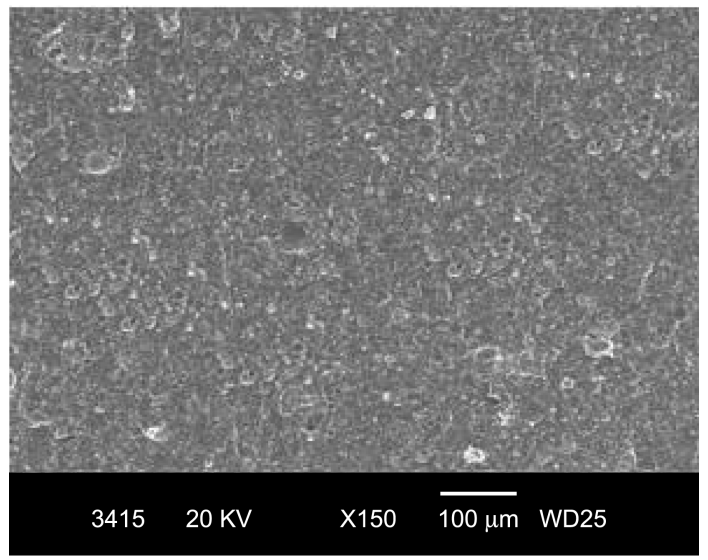

3) N-MPGE + Co(II) complex

Figure 3. Fractured morphology analysis of cured maleimidophenyl glycidylether with different amines. 1) $N$-MPGE $+\mathrm{Cu}(\mathrm{II})$ complex, 2) $N$-MPGE + Ni(II) complex, and 3) $N$-MPGE + Co(II) complex. ing metal ions clearly indicate that the thermal stability of cured resins was improved with the incorporation of metal ions into the malemide epoxy resin. ${ }^{21}$ With the incorporation of the metal ions into $N$-MPGE which increases the initial decomposition temperature (IDT) of the maleimide epoxy containing metal ions (Table 1). On the other hand, the integral procedural decomposition temperature (IPDN) also systematically increased with incorporation of metal ions. The high IPDT indicates that the cured $N$-MPGE containing copper, nickel and cobalt ions show good thermal stability.

Morphology Studies of Cured Systems. The morphology of fracture surfaces of cured $N$-MPGE containing $\mathrm{Co}(\mathrm{II}), \mathrm{Ni}(\mathrm{II})$ and $\mathrm{Cu}(\mathrm{II})$ ions was examined using scanning electron microscope. All the systems exhibit similar morphology. From Figure 3 it is clearly seen that the fracture surfaces of the neat $N$-MPGE containing $\mathrm{Co}(\mathrm{II}), \mathrm{Ni}$ (II) and $\mathrm{Cu}$ (II) ions exhibit a homogenous pattern. All the cured samples exhibit similar homogeneous network and show no formation of distinct domains, confirming the formation of a homogeneous network in all the cured systems.

Moisture and Chemical Resistance Measurements of Cured Systems. Figure 4 shows the water/acid/alkali/ solvent resistance of $N$-MPGE with $\mathrm{Cu}$ (II) complex. All the three systems show similar trend in chemical and water absorption resistance and the results are in Table 5. The goal of this study was to describe the interactions between the absorbed moisture and the epoxy network. The transport of moisture through the epoxy network involves cooperative motion of water molecules and 3-dimensional resin network. One of the major factors affecting water absorption is the presence or absence of hydrophilic groups in the crosslinked network. There are the same types of hydrophilic groups in the present systems. There are also other relevant factors to consider, notably free volume, which generally increases with cross-link density because of the development of a rigid macromolecular framework.

Figure 4 clearly shows that initially there is a sharp increase in water absorption due to water penetration into

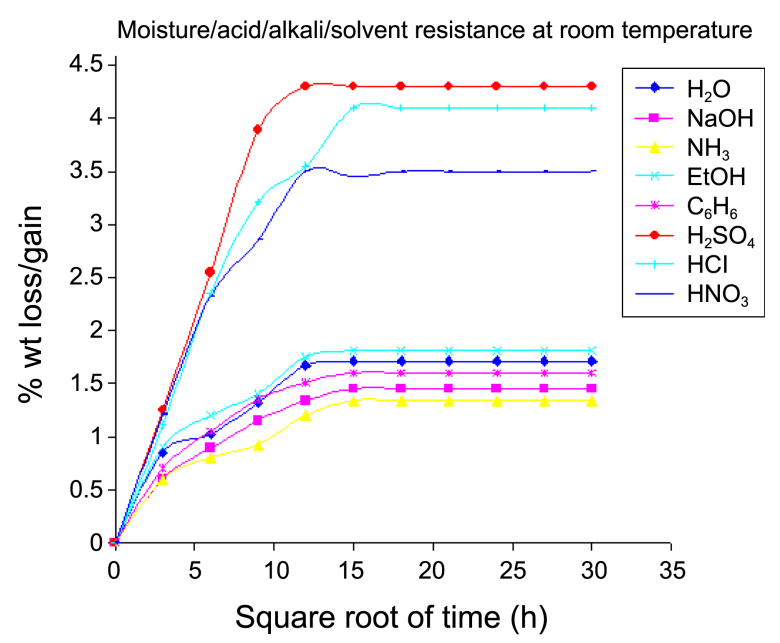

Figure 4. Water/Acid/Alkali/Solvent resistance of $N$-MPGE with $\mathrm{Cu}(\mathrm{II})$ complex. 
Table 5. The maximum moisture/acid/alkali/solvent resistance content at room temperature $\left(25^{\circ} \mathrm{C}\right)$

\begin{tabular}{|c|c|c|c|c|c|c|c|c|}
\hline \multirow{2}{*}{ System } & \multicolumn{5}{|c|}{$\%$ Weight gain } & \multicolumn{3}{|c|}{$\%$ Weight loss } \\
\hline & $\mathrm{H}_{2} \mathrm{O}$ & $10 \% \mathrm{NaOH}$ & $\mathrm{NH}_{3}$ & $\mathrm{C}_{2} \mathrm{H}_{5} \mathrm{OH}$ & $\mathrm{C}_{6} \mathrm{H}_{6}$ & $\mathrm{H}_{2} \mathrm{SO}_{4}$ & $\mathrm{HCl}$ & $\mathrm{HNO}_{3}$ \\
\hline$N$-MPGE+EDA & 1.62 & 1.82 & 1.59 & 4.09 & 1.38 & 4.28 & 3.85 & 3.60 \\
\hline$N$-MPGE+DETA & 1.57 & 1.89 & 1.49 & 4.01 & 1.45 & 4.30 & 3.71 & 3.58 \\
\hline$N$-MPGE+TETA & 1.59 & 1.93 & 1.58 & 3.95 & 1.56 & 4.31 & 4.09 & 3.50 \\
\hline
\end{tabular}

structural defects and cavities on the surface of samples. After some time a slow process of water absorption reaches its equilibrium at room temperature.

In the case of chemical resistance measurements the cured systems are studied with ammonia. The same trends in weight reduction are observed for all the systems. Initially the weight reduction is faster possibly due to washing some of the unreacted epoxy from surface of the samples. The second step is a slow weight reduction which can be due to washing some of the unreacted epoxy out of the bulk of the samples. The more complex the network is, the longer it takes for ammonia to diffuse in to the system to reach the equilibrium. The plots of moisture absorption vs. square root of time were constructed to note the saturation limits of the absorbed moisture. From Figures 4 it is observed that initially the water uptake increases, and shows a flat profile exhibiting Fickean type behavior. ${ }^{19}$ The cured samples were found to have good chemical resistance (acid/alkali/solvent) and water absorption resistance as compared to traditional epoxy amine cured systems. ${ }^{7,10,20}$ This may be due to of the incorporation of metal ions into $N$-MPGE, which provides a cyclic imide structure and high cross-linking density to the cured resins.

The maximum moisture/acid/alkali/solvent resistance contents under given conditions of temperature in the case of cured $N$-MPGE containing copper, nickel and cobalt ions are shown in Table 5. These data clearly indicate that the cured malemide epoxy containing copper, nickel and cobalt ions show more resistance to water absorption and other chemicals.

\section{Conclusion}

The Schiff base-metal complexes were found as potential curing agents for the thermosetting epoxy resins ( $N$-MPGE). The cured systems exhibited excellent thermal stability and good chemical (acid/alkali/solvent) and water absorption resistance. The bonding of Schiff base to metal ions was confirmed by spectral, magnetic, and thermal studies. As discussed above, the Schiff base ligand acts as a tetradentate using carbonyl oxygen, azomethine nitrogen and piperazine nitrogen atoms as coordination sites for the metal ions.

\section{References}

1. Corhnelissen, J. P.; Van, J. H.; Diemen, L. R.; Groeneveld, J. G.; Haasnoot, A. L.; Spek, J.; Reedisk, Inorg. Chem. 1992, 31, 198.

2. Dubey, S. N.; Kaushik, B. Indian J. Chem. 1985, 24, 950.

3. (a) Kurnoskin, A. V. In Metal-containing Epoxy Polymers; Cheremisinoff, N. P., Cheremisinoff, P. N., Eds.; New York:
Marcel Dekker: 1996; p 703. (b) Kurnoskin, A. V. Journal of Macromolecular Science Reviews in Macromolecular Chemistry and Physics 1996, C36(3), 457. (c) Kurnoskin, A. V. JMS Rev. Macromol. Chem. Phys. 1995, C35(3), 419. (d) Kurnoskin, A. V. Polym. Comp. 1993, 14, 481. (e) Kurnoskin, A. V. Polymer. 1993, 34(5), 1060. (f) Kurnoskin, A. V. Polymer 1993, 34(5), 1077. (h) Kurnoskin, A. V. Ind. Eng. Chem. Res. 1992, 31, 524. (f) Kurnoskin, A. V. Polymer 1993, 34(5), 1077. (h) Kurnoskin, A. V. Ind. Eng. Chem. Res. 1992, 31, 524.

4. (a) Lin, K. F.; Wang, W. H. Polym. Comp. 1995, 16(4), 269. (b) Lin, K. F.; Shu, W. Y.; Wey, T. L. Polymer 1993, 34(2), 277. (c) Lin, K. F.; Shu, W. Y.; Wey, T. L. Polymer 1993, 34(10), 2162.

5. (a) Anand, M.; Srivastava, A. K. Polym. Eng. Sci. 1997, 37(1), 183. (b) Anand, M.; Srivastava, A. K. Angew, Makromol. Chem. 1994, 219, 1. (c) Anand, M.; Srivastava, A. K. J. Appl. Polym. Sci. 1994, 51(2), 203. (d) Anand, M.; Srivastava, A. K. J. Macromol. Sci., Pure Appl. Chem. 1993, A30(5), 435.

6. (a) Lin, K. F.; Shu, W. Y.; Wey, T. L. Polymer 1993, 34(10), 2162. (b) Anand, M.; Srivastava, A. K. Polymer 1993, 34(13), 2860.

7. (a) Shivananda, K. N.; Mahendra, K. N. Bull. Korean Chem. Soc. 2006, 27, 1542. (b) Shivananda, K. N.; Mahendra, K. N. Ira. Poly. Journal 2007, 16(3), 161.

8. Weinberger, P.; Costisor, O.; Tudose, R.; Baumgartner, O. Linert, Mol. Struct. 2004, 21, 519.

9. Rama Krishna Reddy, K.; Mahendra, K. N. Molbank 2006, M, 516.

10. (a) Lakshmi, B.; Shivananda, K. N.; Mahendra, K. N. Bull. Korean Chem. Soc. 2010, 31, 2272. (b) Lee, G.-S.; Lee, Y.-C.; Myoung, S. G. Bull. Korean Chem. Soc. 2001, 22, 1393.

11. (a) Hassaan, M. A.; Shehata, K. Synth. React. Inorg. Met.-Org. Chem. 1993, 25(3), 815. (b) Konstantinovic, S.; Radovanovic, B.; Cakic, Z.; Vasic, V. J. Serb. Chem. Soc. 2003, 68, 641.

12. (a) Murukan, B.; Mohanan, K. Trans. Met. Chem. 2006, 31, 653. (b) Konstantinovic, S.; Radovanovic, B.; Cakic, Z.; Vasic, V. J. Serb. Chem. Soc. 2003, 68, 641.

13. Nakamoto, K. Infrared Spectra of Inorganic and Coordination Compounds, $2^{\text {nd }}$ ed.; Wiley-Inter Science: 1963; 172.

14. Manhas, B. S.; Sardana, A. K.; Kalia, S. B. Syn. Rea. Inorg. Metal-Org. and Nano-Metal Chemistry 2005, 35, 171.

15. Rama Krishna Reddy, K.; Madhusudan Reddy, K.; Mahendra, K. N. Ind. J. Chem. 2006, 45A, 377.

16. Gudasi, K. B.; Patil, M. S.; Vadavi, R. S.; Shenoy, R. V.; Patil, S. A.; Nethaji, M. Trans. Met. Chem. 2006, 31, 580.

17. (a) Thimmaiah, K. N.; Lioyd, W. D.; Chandrappa, G. T. Inorg. Chim. Acta 1985, 160, 81. (b) Gudasi, K. B.; Patil, M. S.; Vadavi, R. S.; Shenoy, R. V.; Patil, S. A.; Nethaji, M. Trans. Met. Chem. 2006, 31,580

18. (a) Jain, M. C.; Shrivastava, A. K.; Jain, P. C. Inorg. Chim. Acta 1977, 199. (b) Canpolat, E.; Yciazi, A.; Kaya, M. Trans. Met. Chem. 2006, 31, 653.

19. (a) Jones, R. R. In Chemistry and Technology of Epoxy Resins; Ellis, B., Ed.; London: Chapman and Hall 1993, 8, 256. (b) Vanaja, A.; Ph.D Thesis, Bangalore University, Bangalore 2003.

20. (a) Lakshmi, B.; Shivananda, K. N.; Mahendra, K. N. Bull. Korean Chem. Soc. 2010, 31, 2272. (b) Lee, G.S.; Lee, Y.-C.; Myoung, S. G. Bull. Korean Chem. Soc. 2001, 22, 1393.

21. Shivananda, K. N.; Mahendra, K. N. Intern. Cong. Chem. Envi. $\mathbf{2 0 0 5}, 2,337$. 